\title{
Physico-chemical Characterization of Cookies Supplemented with Sugarcane Bagasse Fibres
}

\author{
M.P.G. Vijerathna ${ }^{1}$, I. Wijesekara ${ }^{1 *}$, R. Perera ${ }^{2}$, \\ S.M.T.A. Maralanda ${ }^{2}$, M. Jayasinghe ${ }^{1}$ and I. Wickramasinghe ${ }^{1}$ \\ ${ }^{1}$ Department of Food Science \& Technology, Faculty of Applied Sciences, University of Sri \\ Jayewardenepura, Nugegoda, Sri Lanka \\ ${ }_{2}^{2}$ Processing Technology Division, Sugarcane Research Institute, Uda Walawe, Sri Lanka
}

Date Received: 30-04-2019

Date Accepted: 10-05-2019

\begin{abstract}
Sugarcane bagasse is a by-product of sugarcane processing and it is rich in insoluble dietary fibers. The objective of this study was to develop cookies enriched with sugarcane bagasse as a fiber source with no added sugars. Bagasses with or without peel were collected from a jaggery manufacturing plant and they were dried, grinded, and sieved to obtain powder (moisture content, 3\%). The fiber content ( $\%$, wet weight basis) of bagasse powders with and without peel were $12.43 \pm 0.30$ and $8.61 \pm 0.38$, respectively. Furthermore, the bagasse with peel contained the highest total phenolic content $(1270.89 \pm 3.36 \mu \mathrm{g} \mathrm{GAE} / \mathrm{g})$ than bagasse without peel $(721.41 \pm 0.33 \mu \mathrm{g} \mathrm{GAE} / \mathrm{g})$. In addition, water holding capacities (WHC) of with peel and without peel bagasse were 4.85 \pm 2.91 and $8.04 \pm 1.78 \mathrm{~g}$ of water/g of bagasse powder, respectively. These two types of bagasse powders at $0 \%$ (control), 5\%, and $10 \%(\mathrm{w} / \mathrm{w})$ ratios were enriched to develop cookies. Texture analysis revealed that bagasse with peel enriched cookies were shown optimum hardness compare to the bagasse without peel cookies. According to the sensory evaluation, the 5\% bagasse with peel enriched cookies showed the highest overall acceptability than other bagasse enriched cookies but lesser overall acceptability than the control. Collectively, these results suggest that the potential incorporation of sugarcane bagasse (with peel at 5\%, $\mathrm{w} / \mathrm{w}$ ) is acceptable in cookies manufacturing.
\end{abstract}

Keywords: bagasse, by-products, cookies, sugarcane, value-addition

\section{Introduction}

The most common reasons for the increment of diabetic like deceases at present are the use of high sugar (high glycemic index; GI) containing foods, use of highly refined (low fibre) foods (Kurek and Wyrwisz, 2015), and lack of sufficient exercises. Furthermore, the busy life style of people tends to use cookies like ready to eat food products. Normally, cookies contain less fibre content and there is a risk of increment of diabetic like non-communicable deceases due to frequent consumption of low-fibre food products.

Sugarcane bagasse is a by-product at sugar manufacturing process, sugarcane treacle and sugarcane jaggery industries. Currently, in the large scale for example, sugar manufacturing industry in

* Correspondence: isuruw@sci.sjp.ac.lk

Tel: +94768237800

(C) University of Sri Jayewardenepura 
Sri Lanka, burns this bagasse as a bio fuel. However, in the medium and small-scale sugarcane treacle and (15\%), and water (70\%). The bagasse contain mainly fibres such as cellulose (55-58\%), hemicelluloses (26-32\%), and lignin (19-22\%) (Sangnark and Noomhorm, 2004).

Cookies are ready to eat cheap and convenient food product that is consumed among all age groups in many countries (Usman et al., 2015). They are the most popular bakery items because of their high nutritive value, ready-to-eat nature, and easy availability in different shapes and sizes at an affordable cost. Cookies and other sweet baked items are rich in sugar (mainly sucrose) and fat and are usually avoided by calorie-conscious consumers. Functional properties of biscuits can be increased by improving or modifying the major ingredients, namely, flour, sugar, and fat along with supplementation of health-promoting ingredients like whey protein concentrate, skimmed milk powder, and dietary fibres (Aggarwal et al., 2016).

Based on the consumer's demand, food scientists are now focusing on developing low calorie and high fibre functional foods incorporating plant sources for example; biscuits (Aggarwal et al., 2016) and dairy products like drinking yoghurts (Wijesinghe et al., 2018). Therefore, there is a leading trend in the bakery industry to develop cookies incorporated with food fibres. The objective of this study was to develop and physico-chemical characterization of cookies supplemented with sugarcane bagasse fibres.

\section{Materials and methods}

\subsection{Chemicals}

All chemicals used in the present study were of analytical grade and experiments were performed at Food Processing Laboratory, University of Sri Jayewardenepura and Sugarcane Research Institute, Uda Walawa, Sri Lanka.

\subsection{Preparation of with peel bagasse powder (from unpeeled sugarcane stems)}

$5 \mathrm{~kg}$ of freshly harvested sugarcane (variety SL96128) stems was cleaned and weighed and crushed to extract sugarcane juice. At the same time, sugarcane bagasses were collected and weighed. The bagasse yield (\%, wet weight basis) was calculated according to the initial sugarcane stem weight. The bagasse samples were dried in an oven at $65^{\circ} \mathrm{C}$ for $6.5 \mathrm{~h}$ till the final moisture content reached around 3\% (dry basis). Then the dried bagasse samples were ground and sieved to yield with peel bagasse powder followed by packed in HDPE bags and kept in a cool and dry place till further use.

\subsection{Preparation of without peel bagasse powder (from peeled sugarcane stems)}

Similarly, another $5 \mathrm{~kg}$ of freshly harvested and cleaned sugarcane stems (variety SL96128) were subjected to manual peeling to remove the outer peel of the stems. The weight of the peeled sugarcane samples was measured and they were crushed to remove sugarcane juice. Finally, the weight of the yielded bagasse was measured and the bagasse yield (\%, wet weight basis) was calculated according to the initial sugarcane stem weight. The without peel sugarcane bagasse powder was prepared by following the same procedure as described previously for with peel bagasse powder.

\subsection{Biochemical analysis of bagasse powders and cookies}

The moisture content, ash content, and protein content were determined according to standard AOAC official analytical methods. The fat content was analysed according to Majonior method.

\section{Crude fibre content of bagasse powders}

Initially sugarcane was ground to prepare $100 \mathrm{~g}$ of powder. Then it was boiled well and washed thoroughly. Finally, the residue was dried in an oven at $105^{\circ} \mathrm{C}$ for 48 hours. The final weight of the residue was taken as the crude fibre content (\%, wet weight basis). 
Total phenolic content of bagasse powders and cookies

The phenolic content was determined spectrophotometrically with Foling-Ciocalteu's reagent according to the modified method (Singleton et al., 1999). In this analysis, gallic acid was used as reference standard and results were expressed as gallic acid equivalents (GAE, $\mu \mathrm{g} \mathrm{GAE} / \mathrm{g}$ of bagasse or cookie powder).

Water holding capacity (WHC) of bagasse powders

The WHC of sugarcane bagasse powders was determined according to the modified method of Bencini (1986). Dried powder (1.0 g) was suspended with distilled water $(10 \mathrm{ml})$ at room temperature in a pre-weighed centrifuge tube and stirred well for $5 \mathrm{~min}$. Then the mixture was centrifuged at 5,000 $\mathrm{g}$ for $30 \mathrm{~min}$ and the swollen fibre particles was separated from the supernatant and weighed. The WHC was expressed as the weight ( $\mathrm{g}$ ) of water carried by $1 \mathrm{~g}$ of sugarcane bagasse powder.

\subsection{Preparation of cookies}

Cookies were formulated and developed according to a modified method of Simovc et al. (2016) (Table 1). The control samples of cookies were prepared without sugarcane bagasse powder and for the preparation of $5 \%(\mathrm{w} / \mathrm{w})$ and $10 \%(\mathrm{w} / \mathrm{w})$ of with peel and without peel bagasse powder incorporated cookie samples, wheat flour was replaced with the corresponding bagasse powder.

Table 1: The formulation $(\%, w / w)$ of control and bagasse incorporated cookies.

\begin{tabular}{lrcccc}
\hline Components & Control & $\begin{array}{c}5 \% \\
\text { With peel }\end{array}$ & $\begin{array}{c}10 \% \\
\text { With peel }\end{array}$ & $\begin{array}{c}5 \% \\
\text { Without peel }\end{array}$ & $\begin{array}{c}10 \% \\
\text { Without peel }\end{array}$ \\
\hline Wheat flour & 61.0 & 56.0 & 51.0 & 56.0 & 51.0 \\
Bagasse powder & 0.0 & 5.0 & 10.0 & 5.0 & 10.0 \\
Vegetable fat & 13.0 & 13.0 & 13.0 & 13.0 & 13.0 \\
Baking powder & 1.1 & 1.1 & 1.1 & 1.1 & 1.1 \\
Salt & 0.9 & 0.9 & 0.9 & 0.9 & 0.9 \\
Water & 24.0 & 24.0 & 24.0 & 24.0 & 24.0 \\
\hline
\end{tabular}

Initially, wheat flour and vegetable fat were mixed manually for 6 to $8 \mathrm{~min}$. Then previously dissolved salt and baking powder were added to the mixture and kneaded for 15 min to prepare the dough. The resulted dough was rested at room temperature for $2 \mathrm{~h}$. Then, the dough was manually shaped in the appreciated form and circular form of cookies were cut followed by backed in an oven at $180^{\circ} \mathrm{C}$ for $15 \mathrm{~min}$ (the relevant time temperature combination was determined, after conducting preliminary trials). Then the samples were cooled down to room temperature and packed using LDPP and aluminium foils till further analysis.

\subsection{Physico-chemical analysis and characterization of cookies Nutritional composition and $\mathrm{pH}$ value}

The nutritional composition of cookies was determined as described previously in the sugarcane bagasse powder analysis. For the $\mathrm{pH}$ determination, $5 \mathrm{~g}$ of powdered form of cookies were dissolved in $45 \mathrm{ml}$ of distilled water. Then the $\mathrm{pH}$ value of each sample was measured by using a laboratory $\mathrm{pH}$ meter (Hanna ${ }^{\circledR}$ HI 9124, Hanna Instruments Inc., USA) and values were recorded. 
Determination of diameter, thickness, spread ratio and weight of cookies

The diameter and thickness were measured according to Mildner-Szkudlarz et al. (2012) with slight modifications. The diameter $(\mathrm{mm})$ of cookies was measured by laying 10 cookies on a line by edge to edge with a support of a scale and the length of 10 numbers of cookies was measured with a scale and the average value was calculated. For the thickness $(\mathrm{mm}), 10$ cookies were stacked on the top of the other with the support of a scale and the average value was calculated. The spread ratio of cookies was calculated by dividing the diameter of cookies by the thickness of cookies. For the weight measurements, five cookies from each sample were placed in previously weighted petri-dishes and weighted. Then, the average weight of cookies was calculated.

\section{Texture profile analysis of cookies}

For the texture analysis, a cylindrical probe (TA25/1000) was used. The machine (Group field texture analyser) was set for trigger load $5.0 \mathrm{~g}$, test speed $1.00 \mathrm{~mm} / \mathrm{s}$, fixture none and load cell 4,500 g. There were two cycles and recovery time was $1 \mathrm{~s}$. The texture profile parameter; hardness of the control and sugarcane bagasse incorporated cookies were tested.

\section{Colour}

Colour of the cookies were determined using a reflectance Chroma-Meter (Model CR-400, Konica Minolta Camera Co. Ltd., Osaka, Japan) based on the $\mathrm{L}^{*}$ (lightness or brightness), a* (redness/greenness), $b^{*}$ (yellowness/blueness) values. The reflectance Chroma-Meter was standardized using a white plate; reflectance values of $\mathrm{L}^{*}=93.93, \mathrm{a}^{*}=0.3131, \mathrm{~b}^{*}=0.3189$ were used as standards. The colour values $\mathrm{L}^{*}, \mathrm{a}^{*}$, and $\mathrm{b}^{*}$ were recorded at 5 different places of a particular cookie by keeping the measuring head on those 5 places.

\subsection{Sensory evaluation}

A sensory analysis was conducted to understand the impact of colour, odour, texture, taste and overall acceptability of cookies with respect to fibre content. For the sensory evaluation, 5 hedonic scale (extremely like, like, neither like nor dislike, dislike, and extremely dislike) and a panel of 30 trained members was used. Irregular pattern was the numbering of the sample to increase the accuracy of the sensory evaluation.

\subsection{Statistical analysis}

The statistical analysis of data was carried out for some experiments using One-way ANOVA to test the significance of each variable $(\alpha=0.05)$ and followed by comparisons performed using the Tukey test by the statistical software MINITAB 17. SPSS 21 software was used for the sensory evaluation. Microsoft Office Excel was used 2010-graphical presentation of data.

\section{Results and discussion}

\subsection{Yield and biochemical analysis of sugarcane bagasse powders}

Bagasse is a by-product after extracting juice from harvested stems. The generated yield (\%, wet weight basis) of bagasse with peel and without peel were $40.51 \pm 1.94$ and $21.92 \pm 0.038$, respectively. The moisture content (\%, wet weight basis) of with peel and without peel sugarcane bagasses were approximately 48.12\%. According to Sangnark and Noomhorm (2004), the chemical constituents of bagasse are variable with cellulose, hemicellulose and lignin fibres ranging from 55-58, 26-32, and 19$22 \mathrm{~g} / 100 \mathrm{~g}$, respectively. The peel contains high amount of cellulose, hemicellulose, and lignin. The removing of peel, remove high amounts of these fibres. Therefore, with peel bagasse yield was higher than the without peel bagasse. 
The fibre content (\%, wet weight basis) of with peel and without peel sugarcane bagasses were $12.43 \pm 0.30$ and $8.61 \pm 0.38$, respectively. The with peel sugarcane bagasse showed higher fibre content than without peel bagasse. The reason is that the peel contains high amount of fibres. Therefore, the removing of peel, reduces the fibre content of sugarcane bagasse. Fibre content of field beans seed hull, potato peel, beet root peel waste, mango pulp waste, pineapple pulp waste, and whole wheat flour are $16.80,2.30,2.70,0.74,2.10$, and 7.00, respectively (Sreenath et al., 1996). These data suggested that sugarcane bagasse shows comparatively higher fibre content than most of other common food byproducts. Moreover, the fibre content of wheat bran is $11.81 \%$ and after incorporating of wheat bran by $10 \%(\mathrm{w} / \mathrm{w}$ ) to biscuits, the fibre content increases up to $1.73 \%$ from $0.78 \%$ (Gupta and Tiwari, 2014). Interestingly, the sugarcane bagasse contains considerable amount of fibres and the incorporation of sugarcane bagasse powder to biscuits can be increased the fibre content of biscuits.

The proximate compositions of with peel and without peel bagasses were compared (Table 2) and there is a significant difference between the fat content of with peel bagasse powder $(2.33 \pm 0.32)$ and without peel bagasse powder $(1.04 \pm 0.05)$. The sugarcane outer peel contains a wax layer and it has recognised as high amount of polycosanol alcohol. While, removing the peel, reduces the amount of wax. Therefore, with peel bagasse powder contains higher amount fat than without peel bagasse powder. Moreover, the with peel bagasse powder has a higher amount of protein content compared to without peel bagasse powder. However, sugarcane bagasse powder contains an extremely low amount of protein.

Table 2: Proximate composition (\%, dry weight basis) of sugarcane bagasse powders.

\begin{tabular}{lcc}
\hline Composition & $\begin{array}{c}\text { With peel } \\
\text { bagasse powder }(\%)\end{array}$ & $\begin{array}{c}\text { Without peel } \\
\text { bagasse powder }(\%)\end{array}$ \\
\hline Moisture & $2.99 \pm 0.00^{\mathrm{a}}$ & $3.10 \pm 0.10^{\mathrm{a}}$ \\
Protein & $1.73 \pm 0.11^{\mathrm{a}}$ & $1.25 \pm 0.00^{\mathrm{b}}$ \\
Fat & $2.33 \pm 0.32^{\mathrm{a}}$ & $1.04 \pm 0.05^{\mathrm{b}}$ \\
Ash & $2.4 \pm 0.01^{\mathrm{a}}$ & $2.52 \pm 0.02^{\mathrm{a}}$ \\
\hline
\end{tabular}

Values for texture profile analysis are means $\pm S D ; n=3$, and means in the same column followed by different letters are significantly different $(p<0.05)$.

Furthermore, there is a significant difference in the ash content between with peel bagasse powder and without peel bagasse powder. However, sugarcane bagasse powder contains higher amount of ash content than wheat flour, aestivum wheat bran, and durum wheat bran $(0.60 \pm 0.01,4.58 \pm 0.02$, and $3.04 \pm 0.01 \%$, respectively) (Ellouze-Ghorbel et al., 2010).

The total phenolic contents ( $\mu \mathrm{g}$ GAE/g) of with peel and without peel bagasse powders were $1270.89 \pm 3.36$ and $721.41 \pm 0.33$, respectively. The total phenolic content of with peel bagasse powder was higher than the total phenolic content of without peel bagasse powder. The peel contains high amount of phenolic compounds, therefore the removing of the peel, reduces the most of phenolic contents in the without peel bagasse powder. The total phenolic content of white grape pomace contains 31.22 $\pm 0.45 \mathrm{mg}$ GAE/g (Szkudlarz et al., 2012). Therefore, sugarcane bagasse powders contain comparatively lower phenolic compounds, than white grape pomace.

\subsection{Water holding capacity (WHC) of sugarcane bagasse powders}

The WHC of with peel and without peel bagasse powders were $4.85 \pm 2.91$ and $8.04 \pm 1.78 \mathrm{~g}$ of water/g of dry powder, respectively. The peel contains high amount of lignin and wax. Therefore, with peel bagasse has higher amount of lignin and wax than without peel bagasse powder. Lignin and wax are 
insoluble in water and reduced the water binding ability. Therefore, with peel bagasse powder showed lower WHC than without peel bagasse powder.

\subsection{Properties of cookies}

Nutritional composition and $\mathrm{pH}$ value of cookies

The nutritional composition of sugarcane bagasse incorporated cookies (Figure 1) was analysed and compared with control cookies (Table 3). The moisture content of cookies varies from $2.16 \pm 0.05 \%$ to $2.37 \pm 0.09 \%$. The addition of fibre increases the moisture content of cookies. Moreover, with peel cookies showed lower moisture content than without peel cookies. It has been previously reported that the moisture content of cookies increases, after incorporating concoyam and African wheat flour blends (Igbabul et al., 2015). Further, the moisture content of biscuits increases, after incorporating orange by products dietary fibre. There is not any regular pattern of moisture content of biscuits with respect to the concentration of orange by products dietary fibre (Crizel et al., 2015). Similarly, the incorporation of sugarcane bagasse powders shows an increment of moisture content of cookies. The reason for this consequence is the increment of bagasse powder increases the fibre content, thus increases the moisture content of cookies.

The protein content of cookies samples varies from $9.00 \pm 0.02 \%$ to $11.78 \pm 0.08 \%$. The protein content of cookies decreases, when increasing the concentration of bagasse powder to cookies. Bagasse powder contains low amount protein, therefore the incorporation of fibre to cookies reduces the protein content. Moreover, with peel bagasse incorporated cookies showed higher amount of protein than without peel cookies.

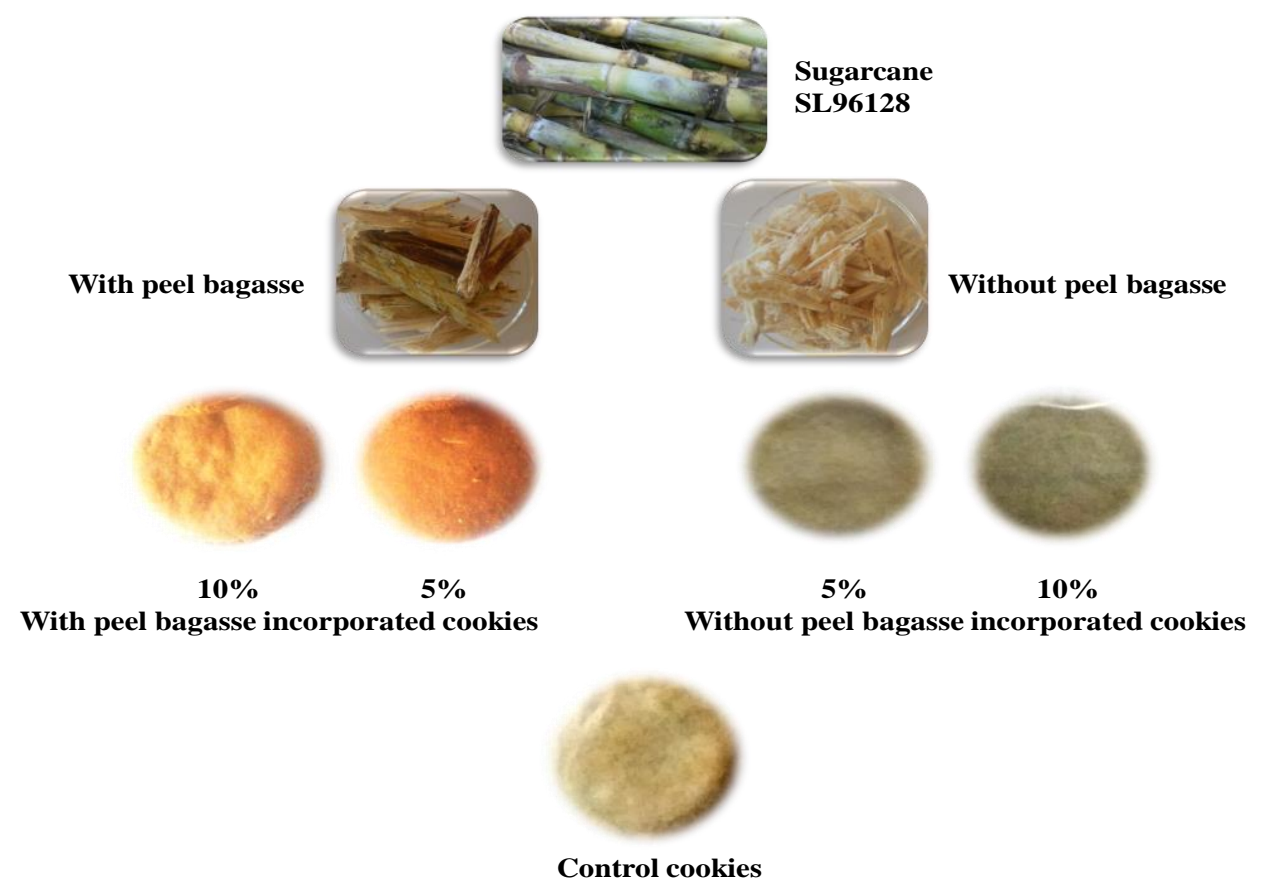

Figure 1. Development of sugarcane bagasse incorporated cookies. 
Table 3: Nutritional composition (\%, dry weight basis) of cookies.

\begin{tabular}{lccccc}
\hline Composition & Control & $\begin{array}{c}5 \% \\
\text { with peel }\end{array}$ & $\begin{array}{c}10 \% \\
\text { with peel }\end{array}$ & $\begin{array}{c}5 \% \\
\text { without peel }\end{array}$ & $\begin{array}{c}10 \% \\
\text { without peel }\end{array}$ \\
\hline Moisture & $2.16 \pm 0.05^{\mathrm{b}}$ & $2.19 \pm 0.09^{\mathrm{ab}}$ & $2.24 \pm 0.05^{\mathrm{ab}}$ & $2.23 \pm 0.09^{\mathrm{ab}}$ & $2.37 \pm 0.09^{\mathrm{a}}$ \\
Fat & $14.45 \pm 0.03^{\mathrm{c}}$ & $14.51 \pm 0.01^{\mathrm{c}}$ & $14.56 \pm 0.02^{\mathrm{a}}$ & $14.54 \pm 0.01^{\mathrm{b}}$ & $14.58 \pm 0.02^{\mathrm{a}}$ \\
Protein & $11.78 \pm 0.08^{\mathrm{a}}$ & $10.64 \pm 0.20^{\mathrm{b}}$ & $9.56 \pm 0.10^{\mathrm{d}}$ & $10.23 \pm 0.03^{\mathrm{c}}$ & $9.00 \pm 0.02^{\mathrm{e}}$ \\
Ash & $2.21 \pm 0.00^{\mathrm{a}}$ & $2.24 \pm 0.01^{\mathrm{a}}$ & $2.27 \pm 0.03^{\mathrm{a}}$ & $2.27 \pm 0.00^{\mathrm{a}}$ & $2.28 \pm 0.00^{\mathrm{a}}$ \\
\hline
\end{tabular}

Values for texture profile analysis are means $\pm S D ; n=3$, and means in the same row followed by different letters are significantly different $(p<0.05)$.

The fat content of cookie samples varies from $14.45 \pm 0.03 \%$ to $14.58 \pm 0.02 \%$. Although there is a significant difference, when comparing the fat content of cookies among types of cookies, the difference is very low. The control sample is showing the lowest fat content, while $10 \%$ without peel sample is showing highest fat content. When increasing the concentration of sugarcane bagasse powder, the fat content increases. Bagasse powder contains little amount of fat as well as it has high oil holding capacity. Hence, bagasse can hold high amount of fat while baking. Comparatively, wheat flour contains lower amount of fat compared to bagasse powder. The fat content of cookies has increased according to the further addition of bagasse powder. Similarly, the fat content of cookies increases, after incorporating chickpea flour and decrease after incorporating mung bean flour (Noor et al., 2012). The fat content of biscuits increases, after incorporating cocoyam and African wheat flour blends. Moreover, the fat content increases when increasing the concentration of cocoyam and African wheat flour blends (Igbabul et al., 2015). Further, the fat content of biscuits increases after incorporating of eggplant flour (Uthumporn et al., 2015).

The ash content of cookies varies from $2.21 \pm 0.00 \%$ to $2.28 \pm 0.00 \%$. The ash content of cookies increases, when increasing the concentration of sugarcane bagasse powder. Sugarcane bagasse powder has high amount ash content than wheat flour. Therefore, the incorporation of sugarcane bagasse powder increases the ash content. This proves that in a previous study, the ash content of biscuits, increases after incorporating mung bean flour and chickpea flour to biscuits (Noor et al., 2012). The $\mathrm{pH}$ values of cookies vary from $6.86 \pm 0.02$ to $7.02 \pm 0.01$. The $\mathrm{pH}$ value decreases, when increasing the concentration of bagasse powder. The highest $\mathrm{pH}$ value shows, control cookie. The lowest $\mathrm{pH}$ value shows $10 \%$ with peel cookie. Also, the $\mathrm{pH}$ value of without peel bagasse is lower than with peel bagasse incorporated cookies. The addition of isolated fibre reduced the $\mathrm{pH}$ of the cake, when compared to the cake without added fibre. The addition of fibre ingredients would slightly decrease the $\mathrm{pH}$ value of food product (Sreenath et al., 1996). Further, the addition of sugarcane bagasse powder reduces the $\mathrm{pH}$ values, thus clearly indicates the addition of sugarcane bagasse powder increases the fibre content of cookies.

\subsection{Phenolic composition of cookies}

The total phenolic content of cookies varies from $0.31 \pm 0.09$ to $153.30 \pm 1.33 \mathrm{~g} \mathrm{GAE} / \mathrm{g}$ (Table 4). It increased with incorporating sugarcane bagasse powders. The reason is sugarcane bagasse powder contains phenolic compounds. $10 \%$ with peel bagasse powder incorporated cookies showed the highest phenolic content among all cookies. The with peel bagasse powder contains the highest amount of phenolic content than without peel bagasse powder. In a previously published research, the phenolic content of biscuits has increased, after incorporating white grape pomace to biscuits (Mildner-Szkudlarz et al., 2012). When increasing the concentration of the white grape pomace, the amount of phenolics increases (Mildner-Szkudlarz et al., 2012). Similarly, when increasing the content of sugarcane bagasse powder to cookies, the phenolic content increases. 
Table 4: Total phenolic content of cookies.

\begin{tabular}{lc}
\hline Type of cookies & $\begin{array}{c}\text { Total phenolic content } \\
(\mu \mathrm{g} \text { GAE} / \mathrm{g})\end{array}$ \\
\hline Control & $0.31 \pm 0.09^{\mathrm{e}}$ \\
$5 \%$ with peel & $31.07 \pm 1.09^{\mathrm{c}}$ \\
$10 \%$ with peel & $153.30 \pm 1.33^{\mathrm{a}}$ \\
$5 \%$ without peel & $14.03 \pm 0.35^{\mathrm{d}}$ \\
$10 \%$ without peel & $94.24 \pm 0.44^{\mathrm{b}}$ \\
\hline
\end{tabular}

Values for texture profile analysis are means $\pm S D ; n=3$, and means in the same column followed by different letters are significantly different $(p<0.05)$.

\subsection{Physical properties of cookies}

The physical properties of control and sugarcane bagasse incorporated cookies were assessed and presented (Table 5). The diameter of cookies varies from $41.67 \pm 0.58$ to $49.67 \pm 0.58 \mathrm{~mm}$. The results have revealed that the diameter of cookies increases, when increasing the content of sugarcane bagasse powder. Moreover, with peel bagasse incorporated cookies showed lower diameter than without peel bagasse incorporated cookies. According to Noor et al. (2012), the diameter of biscuits increases after incorporating mung bean flour and chickpea flour to biscuits. Similarly, the diameter of biscuits increases, after incorporating cocoyam and African wheat flour blends (Igbabul et al., 2015).

Table 5: Physical properties of cookies.

\begin{tabular}{lrrrrr}
\hline Parameter & Control & $\begin{array}{c}5 \% \\
\text { With peel }\end{array}$ & $\begin{array}{c}10 \% \\
\text { With peel }\end{array}$ & $\begin{array}{c}5 \% \\
\text { Without peel }\end{array}$ & $\begin{array}{c}10 \% \\
\text { Without peel }\end{array}$ \\
\hline Diameter $(\mathrm{mm})$ & $41.67 \pm 0.58^{\mathrm{d}}$ & $45.33 \pm 0.58^{\mathrm{c}}$ & $47.33 \pm 0.58^{\mathrm{b}}$ & $48.33 \pm 0.58^{\mathrm{ab}}$ & $49.67 \pm 0.58^{\mathrm{a}}$ \\
Thickness $(\mathrm{mm})$ & $5.10 \pm 1.00^{\mathrm{a}}$ & $4.70 \pm 1.00^{\mathrm{b}}$ & $4.33 \pm 0.58^{\mathrm{c}}$ & $4.10 \pm 0.00^{\mathrm{d}}$ & $3.93 \pm 0.58^{\mathrm{d}}$ \\
Spread ratio & $8.17 \pm 0.26^{\mathrm{e}}$ & $9.65 \pm 0.32^{\mathrm{d}}$ & $10.93 \pm 0.24^{\mathrm{c}}$ & $11.79 \pm 0.14^{\mathrm{b}}$ & $12.63 \pm 0.33^{\mathrm{a}}$ \\
Weight $(\mathrm{g})$ & $3.96 \pm 0.01^{\mathrm{a}}$ & $3.96 \pm 0.01^{\mathrm{a}}$ & $3.97 \pm 0.01^{\mathrm{a}}$ & $3.97 \pm 0.01^{\mathrm{a}}$ & $3.98 \pm 0.00^{\mathrm{a}}$ \\
\hline
\end{tabular}

Values for texture profile analysis are means $\pm S D ; n=3$, and means in the same row followed by different letters are significantly different $(p<0.05)$.

The thickness of cookies varies from $39.33 \pm 0.57$ to $51.00 \pm 1.00 \mathrm{~mm}$. According to the results, the thickness of cookies has increased with the content of bagasse powder. Moreover, with peel bagasse incorporated cookies showed lower thickness than without peel bagasse incorporated cookies. It has been reported that the thickness of the biscuits has decreased with the addition of cocoyam and African wheat flour blends (Igbabul et al., 2015). This could be explained on the basis of an increase in hydrophilic starch granules in cocoyam and African yam bean flours leading to moisture absorption and increase in diameter of the cookies. Thickness of the cookies gradually decreases, when increasing the concentration of wheat bran. The reason for that consequence is the high-water absorbance capacity of wheat bran (Gupta and Tiwari, 2014). The high-water absorption characteristic of fibre (insoluble fibre of pitaya peel; 56.50\%) (Jamilah et al., 2011) can attract more water, thus, the dough viscosity decreased, leading to decreased thickness (Ho and Abdul Latif, 2016). The without peel sugarcane bagasse powder has high water holding capacity than with peel sugarcane bagasse. Therefore, the incorporation of without peel sugarcane bagasse, decreases the thickness of cookies.

The spread ratio of cookies varies from $8.17 \pm 0.26$ to $12.63 \pm 0.33$. The thickness of biscuits increases, when increasing the concentration of with peel bagasse powder. Hence, with peel bagasse incorporated cookies showed lower spread ratio compare to without peel bagasse added cookies. 
The weight of cookies varies from $3.96 \pm 0.01$ to $3.98 \pm 0.00 \mathrm{~g}$. The weight of cookies was not significantly but marginally increases with the amount of sugarcane bagasse powder. Moreover, with peel bagasse added cookies showed marginally lower weight than without peel bagasse added cookies. Similarly, the weight loss of cookies was unaffected by partial submission of piyata peel flour to cookies (Ho and Abdul Latif, 2016).

\subsection{Texture profile analysis (hardness) of cookies}

The hardness of cookies has increased with amount of sugarcane bagasse powder. The hardness of control cookies was $1760.2 \pm 140.9 \mathrm{~g}$, while the hardness values for with peel and without peel at $5 \%$ $(\mathrm{w} / \mathrm{w})$ were $1929.6 \pm 128.6$ and $5627.0 \pm 310.0 \mathrm{~g}$, respectively. The hardness values for with peel and without peel added at $10 \%(\mathrm{w} / \mathrm{w})$ were $9350.0 \pm 501.0$ and $12120.0 \pm 735.0 \mathrm{~g}$, respectively. Cookies prepared from high absorption dough tend to be extremely hard (Noor et al., 2012). A few studies have published previously showed that there was a positive correlation of fibre and protein contents with the hardness value of made cookies. The increase of cookies hardness was observed as the percentage of fibre compound substitution increased (Arora and Camire, 1994). Moreover, the incorporation of bagasse powder showed a clear increment of hardness of cookies. Therefore, this result proves sugarcane bagasse powder is a good source of dietary fibres.

\subsection{Colour of cookies}

The lightness $\left(\mathrm{L}^{*}\right)$ of cookies varied from $54.02 \pm 1.37$ to $64.96 \pm 1.05$ and lightness of $10 \%$ bagasse added cookies was greater than $5 \%$ bagasse added cookies. Moreover, without peel bagasse incorporated cookies showed lower lightness than with peel bagasse incorporated cookies. The reason for this consequence is with peel bagasse is darker in colour than without peel bagasse due to the presence of chlorophyll like pigments and the peel contains high amount of polyphenolic compounds which undergo enzymatic browning and yield melanin like darker compounds. However, Ho and Abdul Latif (2016) reported that the $\mathrm{L}^{*}$ value of biscuits has decreased with the addition of pitaya peel flour. The $\mathrm{a}^{*}$ value (green to magenta) of cookies varies from $8.04 \pm 0.81$ to $12.34 \pm 1.11$. The results revealed that the $a^{*}$ value has decreased with the addition of sugarcane bagasse powder. The with peel bagasse powder added cookies showed lower $\mathrm{a}^{*}$ values than without peel bagasse added cookies. The $b^{*}$ (blue to yellow) value of cookies varies from $25.18 \pm 1.18$ to $30.08 \pm 1.21$. The with peel bagasse incorporated cookies showed lower $b^{*}$ value and without peel bagasse incorporated cookies showed higher $b^{*}$ values compared to the $b^{*}$ values of control cookies.

\subsection{Sensory evaluation}

The attractiveness of control and sugarcane bagasse powders incorporated cookies was investigated with respect to their sensory properties. According to the Kruskal Wallish H test, there is a significant difference between sensory characteristics (appearance, texture, taste, odour, and overall acceptability) of cookies. Therefore, Mann-Whitney Test was conducted. According to the results of Mann-Whitney Test there is not a significant difference between all the sensory characteristics (appearance, texture, taste, odour and overall acceptability) of control and 5\% with peel bagasse added cookies. Moreover, according to the Mann-Whitney test, there is not a significant difference between appearance of control and 5\% without peel bagasse added cookies. Furthermore, the Mann-Whitney test has revealed that there is not a significant difference between all the sensory characteristics of $10 \%$ with peel bagasse added cookies and $10 \%$ without peel bagasse added cookies. According to the sensory analysis results (Figure 2), the highest mean ranks scored for the control cookies and 5\% with peel bagasse added cookies for all tested sensory characteristics. Therefore, with peel sugarcane bagasse at 
$5 \%(\mathrm{w} / \mathrm{w})$ incorporation to cookies can be recommended for the commercial production of sugarcane bagasse incorporated cookies.

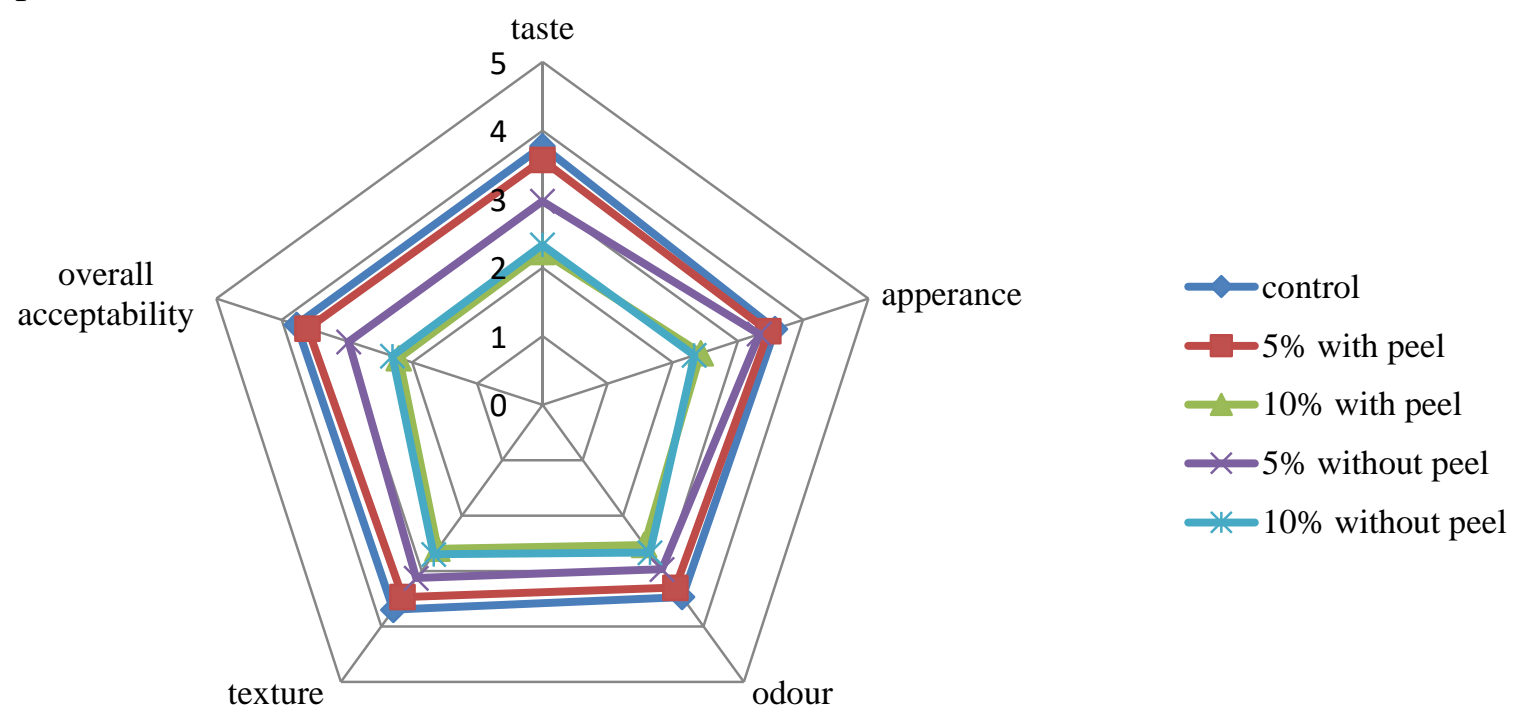

Figure 2. The sensory analysis results of cookies.

\section{Conclusion}

The bagasse with peel powder shows significantly higher amount of protein, fat and phenolic compounds and significantly lower amount of moisture, ash, and WHC values than without peel bagasse powder. The control cookies without any type of sugarcane bagasse sample showed the highest values of $\mathrm{pH}$, protein, and thickness. However, the control cookies showed the lowest values of phenolic content, hardness, spread ratio, fat, ash content, and moisture content. The incorporation of bagasse powder increases the fat content, ash content, moisture content, phenolic content, hardness and antioxidant activity. Sugarcane bagasse (with peel) enriched at 5\% (w/w) showed high protein and phenolic contents with high antioxidant activity and low fat content. Moreover, it has scored high preference according to the sensory evaluation. Collectively, these results suggested that incorporation of sugarcane bagasse with peel at $5 \%$ level could be a promising fibre candidate for cookies.

\section{Acknowledgement}

This study was supported by Sugarcane Research Institute and University of Sri Jayewardenepura, Sri Lanka. Authors wish to thank Ms. Hasanthika Sandarenu, Mrs. H.M.C.K. Herath, Mr. A.M.C.S. Alahakoon, and Dr. Asitha Cooray, Instrument Centre at Faculty of Applied Sciences, University of Sri Jayewardenepura for their technical assistance in proximate analysis.

\section{References}

Aggarwal, D., Sabikhi, L., Kumar, M.H.S., 2016. Formulation of reduced-calorie biscuits using artificial sweeteners and fat replacer with dairy-multigrain approach. NSF Journal, 2:1-7.

Arora, A., Camire, M.E., 1994. Performance of potato peels in muffins and cookies. Journal of Food Research International, 27:15-22.

Bencini, M.C., 1986. Functional properties of drum-dried chick pea (Cicer arietinum L.) flours. Journal of Food Science, 51:1518-1526. 
Crizel, T.D.M., Rios, A.D.O., Thys, R.C.S., Flores, S.H., 2015. Effects of orange by-product fiber incorporation on the functional and technological properties of pasta. Food Science \& Technology (Campinas), 35:546-551.

Ellouze-Ghorbel, R., Kamoun, A., Belguith, S., Ayadi, M.A.L.I., Kamoun, A., Ellouze-Chaabouni, S., 2010. Development of fiber-enriched biscuits formula by a mixture design. Journal of Texture Studies, 41:472-491.

Gupta, S.M.P., Tiwari, A., 2014. Development of high fibre biscuits using wheat bran. Interntional Journal of Engineering \& Innovative Technology, 4:90-94.

Ho, L.H., Abdul Latif, N.W.B., 2016. Nutritional composition, physical properties, and sensory evaluation of cookies prepared from wheat flour and pitaya (Hylocereus undatus) peel flour blends. Cogent Food \& Agriculture, 58:1-10.

Igbabul, B.D., Iorliam, B.M., Umana, E.N., 2015. Physicochemical and sensory properties of cookies produced from composite flours of wheat, cocoyam and African yam beans. Journal of Food Research, 4:150-158.

Jamilah, B., Shu, C.E., Kharidah, M., Dzulkifly, M.A., Noranizan, A., 2011. Physico-chemical characteristics of red pitaya (Hylocereus polyrhizus) peel. International Food Research Journal, 18:279-286.

Kurek, M., Wyrwisz, J., 2015. The application of dietary fibre in bread products. Journal of Food Processing \& Technology, 6.

Mildner-Szkudlarz, S., Bajerska, J., Zawirska-Wojtasiak, R., Gorecka, D., 2012. White grape pomace as a source of dietary fibre and polyphenols and its effect on physical and nutraceutical characteristics of wheat biscuits. Journal of the Science of Food \& Agriculture, 93:389-395.

Noor, A.A.A., Noor, M.A.Y., Ho, L.H., 2012. Physicochemical and organoleptic properties of cookies incorporated with legume flour. International Food Research Journal, 19:1539-1543.

Sangnark, A., Noomhorm, A., 2004. Effect of dietary fiber from sugarcane bagasse and sucrose ester on dough and bread properties. LWT-Food Science \& Technology, 37:697-704.

Simovic, D.S., Maravic, N., Seres, Z., Misan, A., Pajin, B., Jervic, L.R., Podunavac-Kuzmanovic, S.O., Kovacevic, S., 2017. Antioxidant capacity of cookies with non-modified and modified sugar beet fibers: chemometric and statistical analysis. European Food Research \& Technology, 243:239246.

Singleton, V.L., Orthofer, R., Lamuela Raventos, R.M., 1999. Analysis of total phenols and other oxidatant substrates and antioxidants by means of Foling-Ciocaltea reagent. Methods of Enzymologhy, 299:152-178.

Sreenath, H.K., Sudarshanakrishna, K.R., Prasad, N.R., Santhanam, K., 1996. Characteristics of some fiber incorporated cake preparations and their dietary fiber content. Starch, 48:72-76.

Usman, G.O., Ameh, U.E., Alifa, O.N., Babatunde, R.M., 2015. Proximate composition of biscuits produced from wheat flour and maize bran composite flour fortified with carrot extract. Journal of Nutrition \& Food Sciences, 5.

Uthumporn, U., Woo, W.L., Tajul, A.Y., Fazilah, A., 2015. Physico-chemical and nutritional evaluation of cookies with different levels of eggplant flour substitution. CyTA-Journal of Food, 13:220226.

Wijesinghe, J.A.A.C., Wickramasinghe, I., Sarananda, K.H., 2018. Optimizing organoleptic properties of drinking yoghurt incorporated with modified kithul (Caryota urens) flour as a stabilizer and evaluating its quality during storage. Vidyodaya Journal of Science, 21:36-48. 